\title{
Research on Improving Machining Productivity When External Cylindrical Grinding of 160Cr12Mo Steel
}

\author{
Do Duc Trung ${ }^{1, *}$, Nguyen Hong Son ${ }^{2}$, Nhu-Tung Nguyen ${ }^{1}$ \\ ${ }^{1}$ Faculty of Mechanical Engineering, Hanoi University of Industry, Vietnam \\ ${ }^{2}$ Center for Mechanical Engineering, Hanoi University of Industry, Vietnam
}

Received November 16, 2019; Revised December 13, 2019; Accepted December 17, 2019

Copyright $\odot 2020$ by authors, all rights reserved. Authors agree that this article remains permanently open access under the terms of the Creative Commons Attribution License 4.0 International License

\begin{abstract}
This paper presents the research carried out to improve machining productivity when conducting external cylindrical grinding of $160 \mathrm{Cr} 12 \mathrm{Mo}$ steel on the basis of meeting requirement of surface roughness of workpiece. External cylindrical grinding test of 160Cr12Mo steel was based on the optimal test matrix based on symmetrical $\mathrm{D}$ with $\mathrm{Al}_{2} \mathrm{O}_{3}$ grinding wheel. The test data was analyzed to develop regression function to show the relationship between surface roughness with cutting parameters including cutting velocity, depth of cut and feed rate. Basing on this regression equation, the level of influence of each cutting parameters on surface roughness of workpiece was determined, thereby solutions could be found to improve grinding productivity by increasing the depth of cut but meeting the required roughness value. The test was carried out when it was desirable to improve machining productivity but meeting the machining surface having small roughness. The results showed that it is feasible to increase the depth of cut to increase machining productivity up to 1.8 times while the surface roughness also increases only about $0.6 \mu \mathrm{m}$.
\end{abstract}

Keywords External Cylindrical Grinding, 160Cr12Mo Steel, Surface Roughness, Improving Grinding Productivity

\section{Introduction}

In mechanical process, grinding method is always chosen to process surface of workpiece that requires high precision and gloss surface. When researching grinding methods in general and external cylindrical grinding in particular, in addition to focus on research on improving surface quality, especifically reducing surface roughness of workpiece, researchers often concentrate on researches on improving grinding productivity. Many researches on the determination of technological regime (cutting parameters, dressing, lubricant technology, etc.) to reduce surface roughness of workpiece and improve productivity of grinding process have been published, corresponding to each specific case of machining conditions (grinding wheel, processing materials, etc.). The parameters of cutting parameters are the commonly selected parameters as input parameters during research process because they can be simply adjusted and consistent with actual production.

Ganesan et al. [1], Ramesh Rudrapati et al. [5] researched to determine the optimal value of cutting velocity, feed rate and depth of cut when grinding stainless steel 304. The optimal value of cutting velocity, feed rate and depth of cut to produce a small surface roughness when grinding steel C40E was carried out by Naresh Kumar et al. [2]. The optimal value of cutting velocity, depth of cut and number of grinding strokes during the run-off period of grinding steel for OHNS molding was determined by Melwin Jagadeesh Sridhar et al. [3]. Kiyak et al. [4] researched the relationship between surface roughness with cutting velocity and feed rate when grinding AISI1050 steel by $\mathrm{SiC}$ wheel (grain level 60). That relationship allows determining value of the cutting velocity, feed rate and depth of cut basing on specific requirements of surface roughness. The determation of optimal value of cutting velocity, feed rate and depth of cut for smallest surface roughness when grinding ШX15 steel by Hai Duong grinding wheel was conducted by Hoang Tien Dung et al. [12]. Mukesh Kumar et al. [6] researched the influence of cutting velocity, velocity of part, depth of cut, size of grain, flow of cool fluid and number of grinding strokes to surface roughness and material removal capacity when grinding $\mathrm{EN}-47$ steel by $\mathrm{Al}_{2} \mathrm{O}_{3}$ wheel with 3 different sizes grinding grains of 36,46 and 60 . These relationships are the basis for determining value of technological parameters to lessen surface roughness and improve machining 
productivity. The determination of the value of cutting velocity, feed rate and depth of cut when grinding En-19 steel in different hardness states (30, 40 and 50HRC) to ensure the machining surface having smallest roughness and the highest machining productivity was performed by Karande et al. [7]. Mekala et al [8] determined the value of cutting velocity, feed rate and depth of cut so that the speed of removal of material can reach maximum value when grinding AISI 316 steel etc.

According to the above published researches, it's clear that many researches on determination of value of cutting velocity, feed rate and depth of cut to process surface of part with small roughness and high processing rates have been conducted. However, for those researches, the value of the parameters of cutting parameters is only suitable for each specific case; it is difficult to apply to process different types of materials by different wheels. Furthermore, for those researches, for each case, the authors usually only gave out a set of values of the cutting parameters to ensure the smallest value of the surface roughness or a set of value of the cutting parameters to have highest processing capacity, or to solve the multi-parameter optimization problem to determine value set of the cutting parameters to process surface of part with small roughness and high machining productivity. In fact, basing on the relationship between cutting parameters and surface roughness of workpiece (it's normally in the form of regression equations after grinding), it is probable to identify more than one set of cutting parameters having constant or almost constant roughness values and these sets of values sometimes give different capacity when they are applied to the grinding process.

The grinding test of 160Cr12Mo steel conducted within this research to develop regression function showing the relationship between surface roughness of workpiece with parameters of cutting velocity, feed rate and depth of cut, then analyzing the regression function to determine value of these parameters to increase machining productivity but meeting surface roughness requirements.

\section{Grinding Experiment}

\subsection{Grinding Machine}

Tests were carried out on a Toyoda - Japan external cylindrical grinding machine (Figure 1) at a mechanical factory of Viet Thanh Trading Limited Company - Bac Duyen Hai industrial cluster, Duyen Hai Ward, Lao Cai City, Lao Cai Province, Viet Nam.

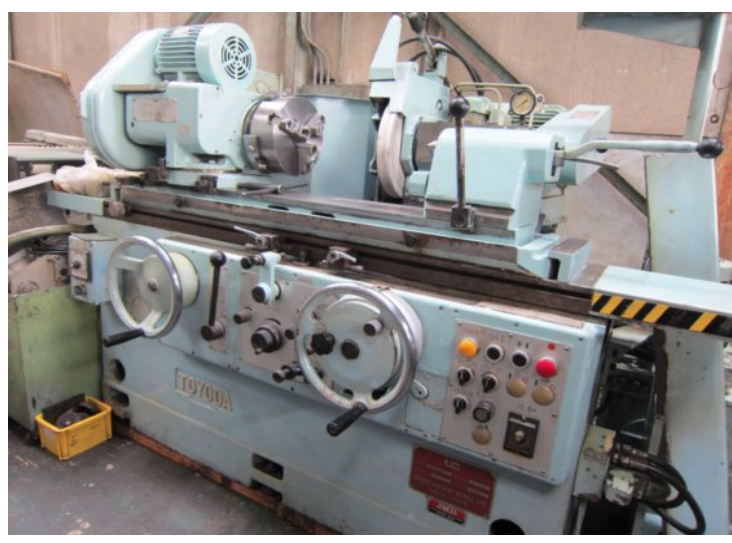

Figure 1. Experimental machine-tool

\subsection{Workpiece}

The workpiece material was $160 \mathrm{Cr} 12 \mathrm{Mo}$ steel. This is a representative steel for high alloy steel group which is broadly used to manufacture machine parts requiring high precision and gloss surface through grinding technology. The symbol of this steel of some countries is shown in Table 1. The workpieces are heat-treated reaching 62 HRC hardness, and are semi-finish grinded finely before testing. The shape and size of the sample test are shown in Figure 2.

Table 1. The symbol of 160 Cr12Mo steel of some countries

\begin{tabular}{|c|c|c|c|}
\hline Vietnam & Russia & America & Japan \\
\hline 160 Cr12Mo & X12M & D2 & SKD11 \\
\hline
\end{tabular}

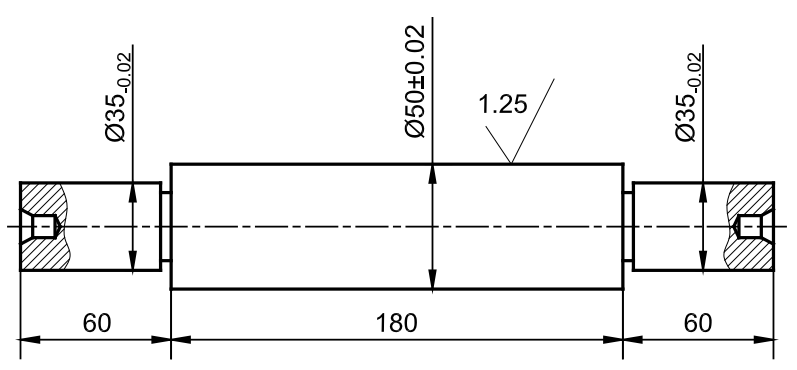

Figure 2. Experimental component

\subsection{Grinding Wheel}

The grinding wheel used in this research is the grinding wheel produced by Hai Duong grinding wheel Factory (Vietnam) with symbol of Cn100.TB1.G.V1x400x40x230x40m/s. This type of wheel is widely being used in grinding technology when processing parts requiring high accuracy and gloss surface. According to Banh Tien Long et al [9], this is a proper wheel to grind the above mentioned material. 


\subsection{Surface Roughness Tester}

Surface roughness is measured by Mitutoyo Surftest SJ-301 machine, for each sample grinding, the surface roughness was measured at least 3 times. During the measurement, the gauge probe moved along the length of the experimental samples (perpendicular to the cutting speed). The roughness value at each test site is the average value of successive measurements.

\subsection{Design of Experiment}

Experiment matrix, including the number of tests and sequences of tests developed in the form of optimal plan based on D symmetry. This type of experiment matrix is popularly used within optimal research of machining processes [10], [11], [12].

Optimal experiment matrix based on D was symmetrical with 3 input parameters including cutting velocity, feed rate and depth of cut. During the grinding, each parameter would receive 3 levels of coding value, actual value of each parameter at the coding level as shown in Table 2. The grinding matrix of 13 test points is presented in the Table 3 .

Table 2. Value of input parameters at coding levels

\begin{tabular}{|c|c|c|c|c|}
\hline \multirow{2}{*}{ Parameter } & \multirow{2}{*}{ Code } & \multicolumn{3}{|c|}{ Value at coding levels } \\
\cline { 3 - 5 } & & -1 & 0 & 1 \\
\hline$v(\mathrm{~m} / \mathrm{min})$ & $\mathrm{x}_{1}$ & 26 & 32 & 38 \\
\hline$t(\mathrm{~mm})$ & $\mathrm{x}_{2}$ & 0.005 & 0.01 & 0.015 \\
\hline$f(\mathrm{~m} / \mathrm{min})$ & $\mathrm{x}_{3}$ & 0.3 & 0.45 & 0.6 \\
\hline
\end{tabular}

Table 3. Experiment matrix

\begin{tabular}{|c|c|c|c|c|c|c|c|}
\hline \multirow{2}{*}{ No. } & \multicolumn{5}{|c|}{ Parameter } & \multicolumn{3}{c|}{ Code } & \multirow{2}{*}{$R_{a}(\mu m)$} \\
\cline { 2 - 7 } & $\mathrm{v}(\mathrm{m} / \mathrm{min})$ & $\mathrm{t}(\mathrm{mm})$ & $\mathrm{f}(\mathrm{m} / \mathrm{min})$ & $\mathrm{x}_{1}$ & $\mathrm{x}_{2}$ & $\mathrm{x}_{3}$ & 0.27 \\
\hline 1 & 26 & 0.01 & 0.3 & -1 & 0 & -1 & 0.40 \\
\hline 2 & 26 & 0.01 & 0.6 & -1 & 0 & 1 & 0.36 \\
\hline 3 & 38 & 0.01 & 0.3 & 1 & 0 & -1 & 0.50 \\
\hline 4 & 38 & 0.01 & 0.6 & 1 & 0 & 1 & 0.25 \\
\hline 5 & 26 & 0.005 & 0.45 & -1 & -1 & 0 & 0.40 \\
\hline 6 & 26 & 0.005 & 0.45 & -1 & 1 & 0 & 0.33 \\
\hline 7 & 38 & 0.015 & 0.45 & 1 & 1 & 0 & 0.48 \\
\hline 9 & 38 & 0.005 & 0.3 & 0 & -1 & -1 & 0.22 \\
\hline 10 & 32 & 0.015 & 0.3 & 0 & 1 & -1 & 0.38 \\
\hline 11 & 32 & 0.005 & 0.6 & 0 & -1 & 1 & 0.36 \\
\hline 12 & 32 & 0.015 & 0.6 & 0 & 1 & 1 & 0.55 \\
\hline 13 & 32 & 0.01 & 0.45 & 0 & 0 & 0 & 0.40 \\
\hline
\end{tabular}




\section{Experimental Results and Discussions}

The experiments were carried out as plan shown in Table 3 with value of the input parameters shown in Table 2 . The surface roughness after measurement was included in Table 3 too. As a result, the regression equation was developed and shows the relationship between surface roughness of workpiece with cutting parameters as equation (1). This regression equation has a coefficient of determination $R^{2}=0.9944$, which is very close to the value 1. This confirms that the regression equation (1) has very high compatibility with test data. Moreover, basing on equation (1), ANOVA analysis was conducted and shows result as in table 4 . This table shows that when setting the significance level $\alpha=0.05$, $S$ is defined as the sum of squares between groups (Regression) having value of 0.112 and a sum of squares (Residual error) having value of 0.001 ; $\mathrm{M}$ is the mean square, reflecting the ratio between the sum of squares and degrees of freedom. The critical value attained from the distribution table $\mathrm{F}$ with $\mathrm{F}$-tab $=$ $F_{0.05}=F(9,3)=0.003$. Since $F=59.458$ is much larger than $\mathrm{F}-\mathrm{tab}=0.003$, so the equation (1) is more reliable.

$$
\begin{gathered}
Y=R_{a}=0.40+0.0725 * x_{1}+0.04375 * x_{2}+0.08125 * \\
x_{3}-0.0025 * x_{1}^{2}-0.015 * x_{2}^{2}-0.02 * x_{3}^{2}+0.0025 * x_{1} * \\
x_{2}+0.0075 * x_{1} * x_{3}-1.2 * 10^{-17} * x_{2} * x_{3}
\end{gathered}
$$

It is required to determine the cutting parameters to ensure the roughness surface value to determine value of the cutting parameters to improve machining productivity but meeting requirements of the surface roughness value.
To do this, a survey on the effect of each cutting parameter element on surface roughness should be conducted. Basing on the regression equation (1), when conducting a survey to examine the effect of a certain element on surface roughness, the other two factors will be fixed.

Table 4. ANOVA analysis of regression model

\begin{tabular}{|c|c|c|c|c|c|}
\hline & $\begin{array}{c}\text { Degree } \\
\text { freedom }\end{array}$ & $\mathrm{S}$ & $\mathrm{M}$ & $\mathrm{F}$ & $\mathrm{F}$-tab \\
\hline Regression & 9 & 0.112 & 0.012 & 59.458 & 0.003 \\
\hline $\begin{array}{c}\text { Residual } \\
\text { error }\end{array}$ & 3 & 0.001 & 0.000 & & \\
\hline SUM & 12 & 0.113 & & & \\
\hline
\end{tabular}

If fixing 2 out of 3 parameters at the coding level 0 , the regression equation of the effect of each parameter on surface roughness will be presented in Equations (2), (3) and (4). Thereby, the graph is developed and shown as in Figure 3.

$$
\begin{gathered}
y_{1(0)}=0.40+0.0725 * x_{1}-0.0025 * x_{1}^{2} \\
y_{2(0)}=0.40+0.04375 * x_{2}-0.015 * x_{2}^{2} \\
y_{3(0)}=0.40+0.08125 * x_{3}-0.02 * x_{3}^{2}
\end{gathered}
$$

If fixing 2 out of 3 parameters at the coding level 1 , the regression equation of the effect of each parameter on the roughness will be presented in Equations (5), (6) and (7). Thereby, the graph is developed and shown as in Figure 4.

$$
\begin{gathered}
y_{1(1)}=0.40-1.2 * 10^{-17}+0.0825 * x_{1}-0.0025 * x_{1}^{2} \\
y_{2(1)}=0.53+\left(0.05375-1.2 * 10^{-17}\right) * x_{2}-0.015 * x_{2}^{2} \\
y_{3(1)}=0.50+\left(0.08875-1.2 * 10^{-17}\right) * x_{3}-0.02 * x_{3}^{2}
\end{gathered}
$$

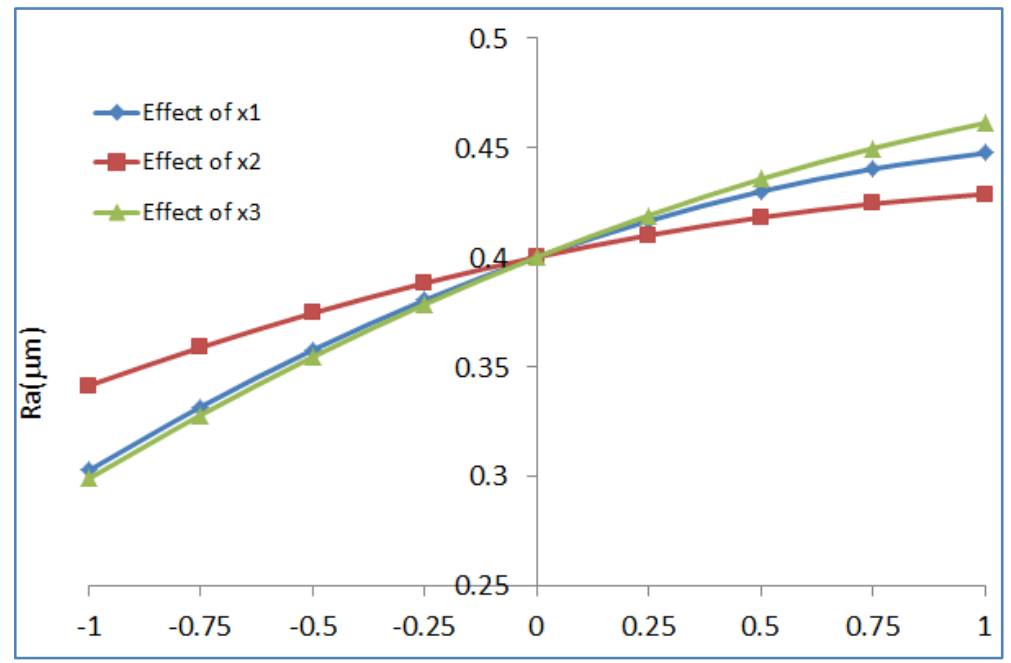

Figure 3. The curve of the sub-regression model when 2 out of 3 parameters at the coding level 0 


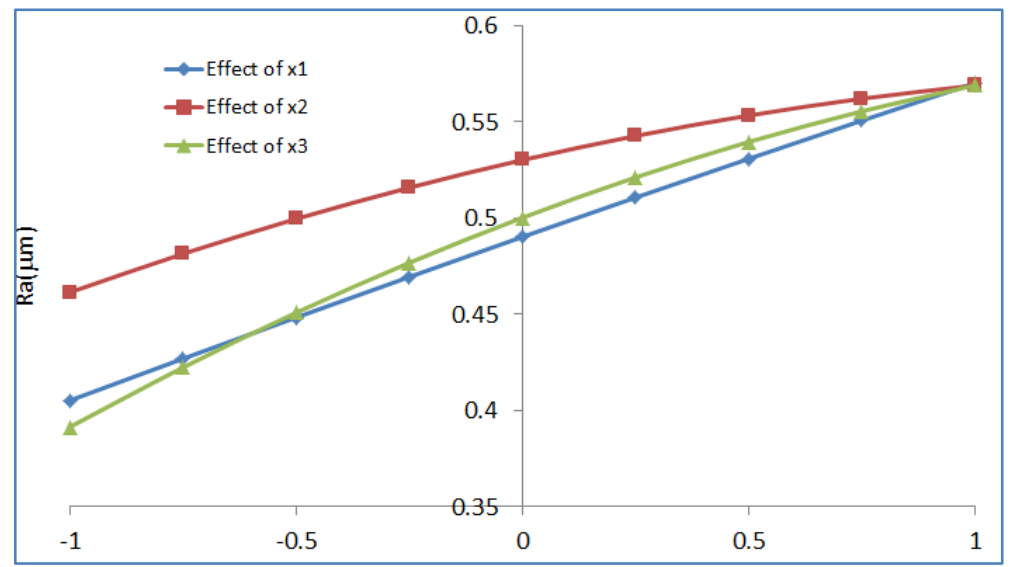

Figure 4. The curve of the sub-regression model when 2 out of 3 parameters at the coding level 1

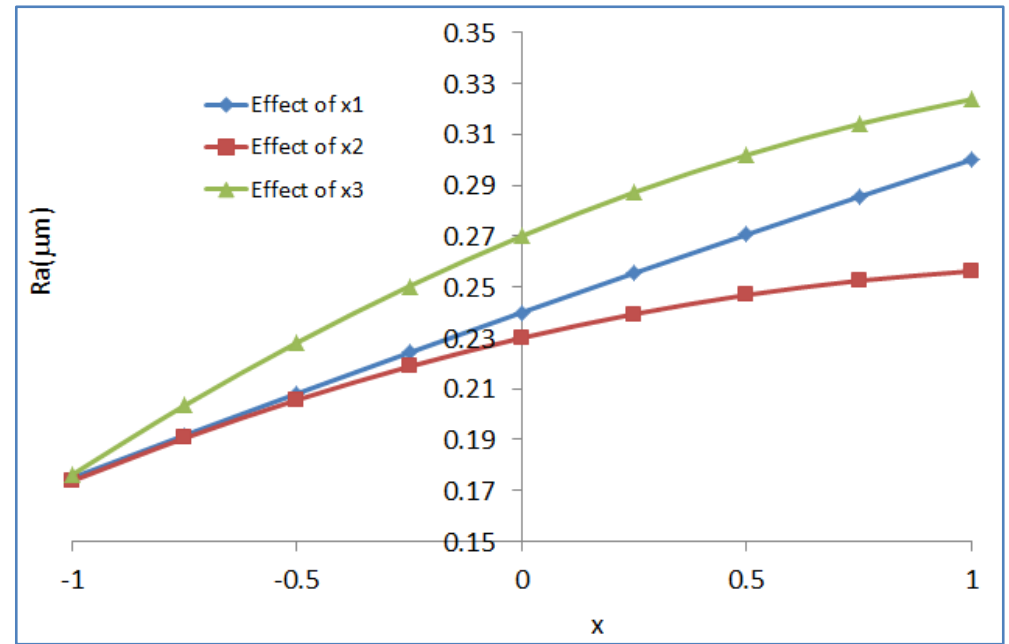

Figure 5. The curve of the sub-regression model when 2 out of 3 parameters at the coding level -1

Likewise, if fixing 2 out of 3 parameters at the coding level -1 , the regression equation of the effect of each parameter on the surface roughness will be presented in the formula (8), (9) and (10). Thereby, the graph is developed and shown as in the figure 5 .

The figures 3, 4 and 5 show that: In all 3 cases, $\mathrm{x}_{3}$ (feed rate) has greatest effect on surface roughness, followed by the degree of influence of $\mathrm{x}_{1}$ (cutting velocity) and finally the degree of influence of $x_{2}$ (depth of cut). Thefore, it is clear that in order to process part's surface with roughness meeting requirements: the change range of feed rate will be in a narrow range. For the change range of cutting velocity it may be wider than the changing range of the feed rate but will be narrower than the change range of the depth of cut. Besides, for cutting velocity, in fact it cannot be changed in a too wide range because this parameter is influenced by the permissible smallest and largest velocity of the wheel. Thus, only the depth of cut is capable of changing with a relatively large range and ensuring value of surface roughness. And obviously, when the depth of cut is increased, the machining productivity will be increased. The question is how to increase the depth of cut to increase machining productivity while ensuring the surface roughness as required. It depends on value of roughness requirements in each specific cases.

$y_{1(-1)}=0.24-1.2 * 10^{-17}+0.0625 * x_{1}-0.0025 * x_{1}^{2}$

$y_{2(-1)}=0.23+\left(0.04125+1.2 * 10^{-17}\right) * x_{2}-0.015 * x_{2}^{2}(9)$

$y_{3(-1)}=0.27+\left(0.07375+1.2 * 10^{-17}\right) * x_{3}-0.02 * x_{3}^{2}$

\section{Determine the Cutting Mode to Improve Machining Productivity}

Supposing to that the value of $\mathrm{x}_{1}, \mathrm{x}_{2}$ và $\mathrm{x}_{3}$ is determined, when grinding $160 \mathrm{Cr} 12 \mathrm{Mo}$ steel, the surface roughness reaches the smallest value. Basing on that the regression equation (1) will determine the calculated value for the parameters $\mathrm{x}_{1}, \mathrm{x}_{2}$ and $\mathrm{x}_{3}$ respectively: $-1.00,-1.00$ and -1.00 , with $\mathrm{Ra}(\mathrm{min})=0.175 \mu \mathrm{m}$.

On the basis of the above analyzes, grinding test is carried out by keeping the values of $x_{1}, x_{3}$ and only change the value of $x_{2}$ in some cases to improve machining productivity but meeting smallest roughness of part's surface. Results are presented in Table 5. 
Table 5. Results of grinding test

\begin{tabular}{|c|c|c|c|c|c|c|c|c|}
\hline \multirow{2}{*}{ No. } & \multicolumn{3}{|c|}{ Encode } & \multicolumn{3}{c|}{ Cutting mode } & \multicolumn{2}{c|}{ Ra $(\mu \mathrm{m})$} \\
\cline { 2 - 9 } & $\mathrm{x}_{1}$ & $\mathrm{x}_{2}$ & $\mathrm{x}_{3}$ & $\mathrm{v}(\mathrm{m} / \mathrm{min})$ & $\mathrm{t}(\mathrm{mm})$ & $\mathrm{f}(\mathrm{m} / \mathrm{min})$ & Test value & Calculating value \\
\hline 1 & -1.000 & $\mathbf{- 1 . 0 0 0}$ & -1.000 & 26 & 0.005 & 0.3 & $\mathbf{0 . 1 8 4}$ & 0.175 \\
\hline 2 & -1.000 & $\mathbf{- 0 . 8 0 0}$ & -1.000 & 26 & 0.006 & 0.3 & 0.196 & 0.189 \\
\hline 3 & -1.000 & $\mathbf{- 0 . 6 0 0}$ & -1.000 & 26 & 0.007 & 0.3 & 0.202 & 0.201 \\
\hline 4 & -1.000 & $\mathbf{- 0 . 4 0 0}$ & -1.000 & 26 & 0.008 & 0.3 & 0.208 & 0.212 \\
\hline 5 & -1.000 & $\mathbf{- 0 . 2 0 0}$ & -1.000 & 26 & 0.009 & 0.3 & $\mathbf{0 . 2 4 3}$ & 0.222 \\
\hline
\end{tabular}

Results in Table 5 shows that: if the value of feed rate and cutting velocity are remained, the depth of cut increases from 0.005 to $0.009 \mathrm{~mm}$, meaning that grinding capacity will increase by 1.8 times, the value of surface roughness changes only about $0.06 \mu \mathrm{m}$. Thus, it is clear that it is possible to increase the depth of cut to improve grinding productivity but meeting requirements for surface roughness.

\section{Conclusions}

The relationship between surface roughness and cutting velocity, feed rate, depth of cut when grinding $160 \mathrm{Cr} 12 \mathrm{Mo}$ steel with Cn100.TB1.G.V1x400x40x230x40m/s grinding wheel was developed in this research. Basing on the analyzed results, it shows that the feed rate has the greatest effect on the surface roughness, followed by the degree of influence of the cutting velocity; the depth of cut has the least impact on the surface roughness.

The feed rate and cutting velocity can only be adjusted in a narrow range to ensure the value of surface roughness achieved to meet a specific requirement. The depth of cut can be changed in a relatively wide range to change grinding productivity but meeting surface roughness value.

This study has shown a method to increase the depth of cutting when grinding to increase machining productivity but still ensuring the value of the surface roughness. When increasing the depth of cut, grinding productivity can be increased up to 1.8 times but the surface roughness only increases $0.6 \mu \mathrm{m}$.

The proposed method in this study is not only applied when grinding the steel 160Cr12Mo but also can apply when grinding other materials, as well as in different machining methods.

\section{Acknowledgements}

This research was conducted with the help of scientists from Hanoi University of Industry (https://www.haui.edu.vn/vn; Corresponding Author: Dr. Do Duc Trung, e-mail: doductrung@haui.edu.vn) and support during the test process at the Viet Thanh Mechanical factory One Member Limited Company, Bac
Duyen Hai Industrial cluster, Duyen Hai Ward, Lao Cai City, Lao Cai Province. The authors would like to express sincere thanks to these organizatons for their help.

\section{REFERENCES}

[1] M. Ganesan, S. Karthikeyan \& N. Karthikeyan, (2014), Prediction and Optimization of Cylindrical Grinding Parameters for Surface Roughness Using Taguchi Method, IOSR Journal of Mechanical and Civil Engineering International Conference on recent trends in engineering and management, pp. 39-46.

[2] Naresh Kumar, Himanshu Tripathi, Sandeep Gandotra, (2015), Optimization of cylindrical grinding process parameters on C40E steel using Taguchi technique, Int. Journal of Engineering Research and Applications, Vol. 5, Issue 1( Part 3), pp. 100-104.

[3] M. Melwin Jagadeesh Sridhar, M. Manickam, V. Kalaiyarasan, M. Abdul Ghani Khan, and Ttm. Kannan, (2014), Optimization of cylindrical grinding process parameters of OHNS Steel (AISI 0-1) rounds using design of tests concept, International Journal of Engineering Trends and Technology (IJETT) - Volume 17 Number 3, pp.109-114.

[4] M. Kiyak, O. Cakir, E. Altan, (2003), A research on surface roughness in external cylindrical grinding, 12th international scientific conference - Achievements in mechanical \& materials engineering, pp. 459-462.

[5] Ramesh Rudrapati, Asish Bandyopadhyay, Pradip Kumar Pal, (2013), Multi-objective optimization in traverse cut cylindrical grinding, Advanced materials manufacturing \& Characterization, Vol 3, Issue 1, pp. 335-340.

[6] Mukesh Kumar, Sukhjinder Singh, Khushdeep Goyal, (2015), To research effect of grinding parameters on surface roughness and material removal rate of cylindrical grinding heated EN47 steel, Journal of Mechanical Engineering, Vol. ME 45, No. 2, pp. 81-88.

[7] Rupesh J. Karande, S.M. Jadhav, Kshitij R. Patil, R. K. Nanwatkar,(2017), Optimization of Cylindrical grinding machine parameters for minimum surface roughness and maximum MRR, Global research and Development journal for engineering, Vol. 2, Issue 5, pp. 62-68.

[8] K Mekala, J Chandradas, K Chandrasekaran, T T M Kannan, E Ramesh and R Narasing Babu, (2014), Optimization of 
cylindrical grinding parameters of austenitic stainless steel rods (AISI 316) by Taguchi method, International journal of mechanical engineering and Robotics Research, pp. 208 215.

[9] Banh Tien Long, Tran The Luc, Tran Sy Tuy (2013), Principles of Materials Processing, Science and Technics Publishing House, Ha Noi.

[10] Nguyen Van Du, Nguyen Dang Binh (2011), Experiment design in technical, Science and Technics Publishing House, Ha Noi.

[11] Pham Van Lang, Bach Quoc Khang (1998), The basis of experimental design theory and application in agricultural engineering, Science and Technics Publishing House, Ha Noi.

[12] Hoang Tien Dung, Do Duc Trung, Nguyen Van Thien, Nguyen Nhu Tung, Ngo Cuong, (2019), Optimization cutting parameters when grinding WX15 steel using Hai Duong grinding wheel, International Journal of Mechanical and Production Engineering Research and Development, Vol. 9, Issue 4, pp. 155-162. 